NBER WORKING PAPER SERIES

\title{
INTERNATIONAL ADVERSE SELECTION IN LIFE INSURANCE AND ANNUITIES
}

\author{
David McCarthy \\ Olivia S. Mitchell \\ Working Paper 9975 \\ http://www.nber.org/papers/w9975
NATIONAL BUREAU OF ECONOMIC RESEARCH 1050 Massachusetts Avenue Cambridge, MA 02138
September 2003

Support for this research was provided by the Pension Research Council at the Wharton School, the National Bureau of Economic Research, the Economic and Social Research Institute of the Government of Japan, and the Wharton-SMU Research Center at Singapore Management University. This study is part of the NBER program on the Economics of Aging. The views expressed herein are those of the authors and not of the institutions with whom the authors are affiliated. The views expressed herein are those of the authors and are not necessarily those of the National Bureau of Economic Research.

(C)2003 by David McCarthy and Olivia S. Mitchell. All rights reserved. Short sections of text, not to exceed two paragraphs, may be quoted without explicit permission provided that full credit, including (C) notice, is given to the source. 
International Adverse Selection in Life Insurance and Annuities

David McCarthy and Olivia S. Mitchell

NBER Working Paper No. 9975

September 2003

JEL No. G2, J1, J3

\section{$\underline{\text { ABSTRACT }}$}

This paper evaluates the extent of adverse selection in life insurance and annuities in international markets, for both group and individual products. We also compare results with prior analyses of adverse selection in international annuity markets, focusing on the US, the UK, and Japan. Our results help assess the extent to which life insurers can hedge mortality exposure by writing both life insurance and annuities, and they may be used to determine a normal range for adverse selection in international insurance markets.

David McCarthy

Imperial College Business School

Room 312

South Kensington

London SW7 2AZ

david.mccarthy@ageing.ox.ac.uk

Olivia S. Mitchell

The Wharton School

3641 Locust Walk

Room 304 CPC

Philadelphia, PA 19104-6218

and NBER

mitchelo@wharton.upenn.edu 


\title{
International Adverse Selection in Life Insurance and Annuities
}

\author{
David McCarthy and Olivia S. Mitchell
}

Insurance specialists recognize that well-functioning insurance markets - in the form of both life insurance products and annuities - are necessary to ensure effective funded retirement systems and efficient national saving. This is because annuities play an essential role in converting asset accumulations into a regular flow of retirement income guaranteed for life, and classical life insurance protects individuals and their dependants from the risk of early death. But as actuaries know, it takes a great deal of statistical information on mortality patterns by age and sex to develop the necessary survival forecasts needed for valuing annuity and insurance products. And in practice, many countries lack a vital statistics collection mechanism, especially for insured lives and annuitants, causing analysts there to rely on mortality data from other countries in order to value insurance products of all types. This paper uses data from three relatively well-developed insurance markets to analyze the differences between the mortality of individuals who have purchased non-annuity insurance products and the general population in these countries. Comparison with previous results permits a comprehensive picture of the effects of adverse selection on mortality and hence on valuation of insurance products in these three markets.

Theory predicts that in the absence of insurance company underwriting, adverse selection will improve the mortality (i.e. increase the life expectancy) of annuity purchasers, but worsen that of purchasers of other life insurance products relative to the general population. We explore the difference between mortality tables for this group in the United States, the United Kingdom, and Japan. Many other countries in the Americas, in Europe, and in Asia use either the US or UK tables to value annuities and insurance. Somewhat surprisingly, our results indicate that 
adverse selection reduces mortality for both life insurance and annuities, contrary to what theory would suggest. This indicates that insurance company screening of potential poorer risks in classic life insurance (“underwriting”) is very effective, possibly even eliminating any asymmetric information held by policyholders.

In Section I we examine the construction of aggregate mortality data (of the type we use here) from records of individual deaths and survivals. Section II briefly presents the standard theory of adverse election in insurance and life annuities. Section III describes the data and results, and Section IV offers conclusions.

\section{Raw and Aggregate Mortality}

It is useful to describe the process by which "raw" data about deaths in a group of people is transformed into aggregate mortality data of the type commonly used by insurance experts. As a rule, "raw" mortality data consists of records of individual deaths and survivals in a population, while aggregate mortality data is usually presented in the form of a mortality table. Such a table is an estimate of the statistical distribution of the remaining life span that can be expected for members of a given population. ${ }^{1}$ A mortality table is generally derived by performing an investigation of deaths occurring in this given population over a specific period of time. Each individual in the population will have one raw data record, which will normally consist of the following information:

1. The date at which the individual entered the investigation;

2. Risk characteristics of the individual (usually age and sex, but may include date of inception of the policy, the type of policy and the reason for the purchase of the policy);

\footnotetext{
${ }^{1}$ For additional background see Bowers et al. (1986), and Faculty and Institute of Actuaries (1999).
} 
3. The date at which the individual left the investigation;

4. The reason for which the individual left the investigation (which may include the end of the investigation, the death of the individual or the lapse of the policy).

The investigator counts up the length of time each individual spent in each risk category and then sums these across individuals. The investigator also counts the total number of deaths in each risk category. By dividing the number of observed deaths in each risk category by the total length of time individuals spent in that risk category, the investigator obtains an estimated probability of death for individuals in each risk category. As a rule, the probabilities are smoothed by fitting some sort of hazard rate model or by applying a smoothing algorithm to the raw estimates. ${ }^{2}$ In the final step, smoothed estimates of the probability of death at age $x$ (denoted $q_{x}$ ) are used to construct a complete mortality table. For most ages, $q_{x}$ is extremely small, which implies that a large number of lives must be observed in order to obtain reliable estimates.

In general, mortality patterns differ across segments of the population for many reasons associated with sex, age, and adverse selection. The latter can depend on the type of product purchased, the reason the product was purchased and the length of time since the product was purchased. Separate estimates of mortality are generally produced by age, sex, product type (e.g., annuities and life insurance), reason for product purchase (compulsory or voluntary) and the length of time that the individual has owned the policy ('select' or ultimate tables).

Mortality rates also change over time as a result of past and projected future improvements in life expectancies. Over the last several decades, mortality among older people has dropped rapidly in developed countries, and there reason to believe that this will continue in

\footnotetext{
${ }^{2}$ Smoothing is usually necessary to eliminate random statistical fluctuations from the data. The theoretical justification behind smoothing is that, as true underlying mortality is expected to change smoothly as age changes,
} 
the future (CMIR, 1997). Actuaries have handled this problem by estimating so-called period mortality tables from past data, and then devising separate, forward-looking, cohort mortality tables by extrapolating future trends in mortality. ${ }^{3}$ Of course, anticipated future declines in mortality built into cohort tables are only estimates based on past trends; it is uncommon to allow for future mortality improvements in life insurance standard tables. This is because it is usually prudent for the insurance company to overstate the mortality of life insurance purchasers (whereas in the case of annuitants, it is conservative to understate it). If the recent trend of mortality improvements suddenly reverses, we can expect that in due course insurance companies will adjust life insurance mortality tables for expected worsening mortality. ${ }^{4}$

\section{Adverse Selection in Life Insurance and Annuities}

It is not uncommon for insurers to be concerned about adverse selection in the markets for both annuities and life insurance. Adverse selection arises because of information asymmetries between the insurer and the insured. People who purchase insurance are generally more likely to have "inside" information about their future mortality, as compared to the insurance companies who sell the products. ${ }^{5}$ This implies that there will be a systematic difference between the observed mortality of people who purchase annuities and life insurance products, and those who do not, holding all else constant. In particular, individuals who believe that their mortality is low will find insurance at a given price more expensive, than those who believe that their mortality is high, and hence will purchase less (or zero) insurance, ceteris

the raw estimate of mortality at age $x$ provides information not only about the true level of mortality at age $x$ but also at ages close to $x$.

${ }^{3}$ In the UK, actuaries assume that mortality improvements are constant across product types, and fit an agedependant model of mortality improvements to a historical database of tables. This model is used to predict future improvements.

${ }^{4}$ This actually happened in the late 1980's when many insurance companies loaded their insurance rates (but not their annuity rates!) for the expected impact of AIDS. 
paribus. Similarly, individuals who believe that their mortality is low will find annuities of a given price better value than individuals who believe that their mortality is high, and should purchase more, ceteris paribus.

If individuals' beliefs about their own mortality are positively correlated with their true underlying mortality, then after controlling for all other relevant variables, a systematic difference between the mortality of those who purchase annuities or insurance and those who do not will emerge. In particular, individuals who purchase life insurance should show higher mortality than those who have not purchased insurance, after controlling for information common to the insurance company and the individual. Similarly, purchasers of annuities should show lighter mortality than a control group. In addition, there will be a systematic relationship between the quantity of insurance or annuities bought and the observed mortality of purchasers, again holding all else constant. ${ }^{6}$ The extent of adverse selection is also affected by the reason the individual purchased the insurance product. If the individual is compelled to purchase the product (possibly by law, by virtue of membership in a retirement fund, or because of some other decision such as taking out a mortgage), then the effect of adverse selection will likely be less severe than if the individual purchased the product voluntarily.

Insurance companies collect information about individuals before deciding at what price to sell insurance or annuities to them. Since this information is common to both insurer and purchaser, it should ideally be controlled for when testing for adverse selection. Such information usually includes age and sex, but sometimes also includes income, occupation, previous and current health status, and the size of the policy applied for. Information that is not easily verifiable (such as current and past health status) is collected by insurance companies

\footnotetext{
${ }^{5}$ Cawley and Philipson (1999) present convincing evidence that insurance companies are better at identifying mortality risk than individuals. Their findings are consistent with our conclusion.
} 
during a process called "underwriting”. During underwriting, applicants for insurance are individually interviewed (often by means of a written questionnaire), and sometimes examined by a medical practitioner. Sub-standard risks are not often rejected for insurance, but are usually offered insurance at a higher price.

In this analysis to follow, only aggregate rather than individual-level data are available. Hence we cannot directly control for these individual risks or their proxies, the price of the insurance or annuity sold. Instead, we omit persons offered insurance at non-standard prices, implying that information common to both insurer and insured is captured by age, sex, the type of product purchased, the date the product was purchased and the reason the product was purchased. This allows us to ignore the effects of price when comparing individuals who buy the same product, but it does not allow us to ignore price when comparing aggregate mortality data of individuals who purchase different products. In order to do this, we must assume that the price-related selection is the same across product types. ${ }^{7}$

Another factor to be considered when assessing the relative of life insurance versus annuities is the structure of the temporal correlation between peoples' perceptions about mortality and the true underlying probabilities. It is reasonable to suppose that this correlation declines over time: in other words, that people are fairly well informed about mortality next year, but they are less well informed about mortality in 20 years' time. If this hypothesis is correct, we would expect that the impact of adverse selection on observed mortality would decline after the policy is purchased. This implies that both a purchaser's age and the length of time since purchase would be important variables correlated with mortality outcomes. For this reason, insurance companies often produce a so-called "select" mortality table for individuals who own

\footnotetext{
${ }^{6}$ In this analysis, the dependence of the price an individual is offered on the extent of adverse selection is ignored. In extreme cases, this dependence can cause markets to fail. See Akerlof (1970) for more details.
} 
policies at short durations, and an "ultimate" mortality table covering purchasers with policies at longer durations. The temporary selection effect is more likely to be important in insurance policies (which may have short durations) than in annuities (which often have long durations).

This effect of selection on mortality is summarized in Figure 1, which shows the stylized mortality rate in a group of individuals as they age. The horizontal axis represents the age of the individuals, increasing from left to right. The vertical axis represents mortality rates of the relevant population. Each of the lines rises from left to right, indicating that mortality, at most ages, increases with age. The top line $(A)$ represents the mortality of a group that has not undergone any selection. The lower bottom line ( $B$, with thin dashes) represents the mortality of a group that underwent selection at age $x$. As can be seen, the extent of selection declines with time as this group's mortality approaches that of the population as a whole (that has not undergone selection). Eventually there is no difference between the mortality of the group that has undergone selection and the group that has not; thus, the selection can be termed “temporary" selection. Finally, the line labeled $C$ (thick dashes) represents the mortality of individuals who underwent selection at age $y>x$. Again, the effect of the selection declines with time, and the mortality of this group approaches that of the other two groups. However, the mortality of this group never equals that of the other two groups, evincing permanent selection as well as temporary selection. This indicates that a group might reflect permanent selection, if the value of the private information it has does not decline with time, if exits from the pool of insured individuals are correlated with mortality, or if mortality is partially endogenous (see Philipson and Becker, 1999).

Figure 1 here

\footnotetext{
${ }^{7}$ Since different insurance products fulfill different needs, policyholders who purchase different products may need to differ in other ways (such as risk aversion, tax status, search costs) in order for this assumption to hold.
} 
Finally, we need to consider the effect of selective exits from the pool of insured individuals. In the first few years that individuals hold insurance policies, lapse rates are usually high. Classical insurance theory predicts that individuals who lapse would tend to have lower mortality than individuals who do not, ${ }^{8}$ producing higher observed mortality in the remaining pool of insured individuals. Note that without separate data on the mortality of individuals who lapse, it is not possible to distinguish this effect from other duration-related effects on mortality.

\section{Metrics for Comparing Mortality Tables}

Having showed the theoretical way in which selection can have a temporary and a permanent effect on mortality, we next examine two empirical methods for comparing mortality tables. Specifically, following Mitchell and McCarthy (2002), we examine plots of age-at-death distributions and the A/E method.

\section{Plots of Age at Death Distributions}

One conventional way to compare mortality tables is to compare the implied distributions of expected age at death. For different mortality tables, this approach requires graphing the percentage of individuals expected to attain age $x$ and die before reaching age $x+1$, given they reached some specific age (65 in the case of annuitants, lower in the case of life insurance purchasers). The graphical approach affords an illustration of which mortality curve is higher, or lower, at given ages. However it does not offer any measure for "how far apart" two mortality tables might be, and it cannot be used to compare the severity of mortality tables at two different ages. This is important when comparing the mortality of annuitants (who tend to be over 65) and purchasers of life insurance (who tend to be under 65).

\footnotetext{
${ }^{8}$ This effect becomes less important the more cash values of policies deviate from economic values. However, in the presence of borrowing constraints, individuals with serious illnesses may surrender policies to pay for medical care, mitigating this effect to some extent.
} 


\section{A/E Method}

An alternative method to compare mortality tables, the "A over E" method, is favored by actuaries and demographers. It expresses the number of deaths expected in a population with a given age structure using one table, and then compares these to the expected number of deaths in a population of the same size using a second mortality table. Results are presented as a ratio multiplied by 100: for example, a value of 100 implies that the same number of deaths is expected in a given population, irrespective of which of the two mortality tables is selected. This measure is mathematically equivalent to a ratio of the weighted average probabilities of death for the two mortality tables, using a specific population structure for the weights.

The particular A/E measure one derives depends on the "baseline" age distribution of the population used to calculate the number of deaths. Therefore it is essential to define the base table clearly, from whence A/E comparisons are then computed as:

$$
\mathrm{A} / \mathrm{E}=\frac{\sum_{x} w_{x} q_{x}^{*}}{\sum_{x} w_{x} q_{x}} \times 100
$$

where $q_{x}^{*}$ is the probability that an individual of age $x$ dies according to the table in question, and $q_{x}$ is the probability that an individual of age $x$ dies according to the base table. The weights, $w_{x}$, are set so that $w_{65}=100,000$, and $w_{x}=w_{x-1}\left(1-q_{x-1}\right)$. The A/E method can be used to compare different mortality tables at different ages.

\section{International Comparisons of Insurance and Population Mortality Tables}

In order to implement these mortality measures, we use aggregate mortality data based on smoothed estimates of mortality produced by others rather than on individual mortality records 
based on "raw" data. This is primarily because the underlying data are proprietary and access is restricted.

\section{A. Data description}

In the US case, mortality data are taken from the US Social Security Administration (1999; see Society of Actuaries, 1999 updated as per Mitchell et al., 1999). For the life insurance portion of this investigation, life tables use the mortality table database maintained by the Society of Actuaries; we use the 1990-1995 series of tables. We also use a 1991 population table from the Social Security Administration, augmented after age 85 by the slightly more recent tables described in Mitchell et. al. (1999). No adjustment is needed to ensure that these tables changed smoothly with age since post-85 mortality has changed little in the last decade. ${ }^{9}$

For the UK case, insurance and annuity mortality tables are produced by the Continuous Mortality Investigation Executive Committee of the Faculty and Institute of Actuaries (1999), and population mortality tables by the Government Actuaries Department (2000). The tables used in the life insurance part of this investigation are the 1992 Series of term and whole life insurance tables produced by the CMIR (1997). The population table is the interim population table for the United Kingdom for the year 1998, produced by the Government Actuaries Department (2000) augmented after age 100 by an earlier table, obtained privately from the Government Actuaries Department (1999). In the case of the male table, probabilities above the age of 100 were adjusted by a constant ratio to ensure that the values in the table changed smoothly. The effects of the choice of adjustment method are extremely small. In the case of the female table, no adjustment was required. ${ }^{10}$ In Japan, the Statistics and Information Department of the Ministry of Health and Welfare (1998) produces population life tables after

\footnotetext{
${ }^{9}$ The tables used in the annuity portion of this investigation are those used by Mitchell and McCarthy (2001) in their investigation of adverse selection in annuities.
} 
each quinquennial census, the most recent available being that of 1995. The Japan Institute of Actuaries (1996) has produced life tables of insured lives in Japan on a regular basis. Their most recent table was published in 1996, along with a table intended to be used to value annuity-style products.

Because the US and the UK data collection mechanisms for mortality experience are relatively consistent, it is widely believed that these two countries produce quite reliable and comparable mortality tables. Accordingly these tables are widely used in both developed and developing nations as a basis for modeling local mortality. In practice, US mortality tables appear to be commonly used in the Western hemisphere, while UK tables are typically employed in countries that were once British colonies or where British influence was strong. ${ }^{11}$ To the best of our knowledge, Japanese mortality tables are not widely used outside the Japanese insurance market.

Several issues arise when using aggregate mortality data in this context. Firstly, and most importantly, the data do not indicate several factors that might affect mortality and that could be also correlated with the decision to purchase insurance; obvious examples include wealth and income. As a result, published data do not allow a direct way of distinguishing the effect on mortality of a correlation between insurance purchase behavior and wealth from permanent effects of adverse selection. We adopt an indirect approach that assumes that these variables affect insurance purchase of all products equally. This implies that any difference between the mortality of, say, annuity purchasers and life insurance purchasers is due only to adverse selection. We also do not have data on the price of insurance offered to any given

\footnotetext{
${ }^{10}$ In the annuity section of the investigation, the tables used are identical to those used by Mitchell and McCarthy (2001) in their investigation of adverse selection in annuities.

${ }^{11}$ See James and Vittas (1999). Often actuarial adjustments are applied to these tables, ostensibly to make them more reflective of local conditions. Lacking good mortality data, however, it is difficult to know what actuarial adjustments might be appropriate.
} 
individual, which reflects the effect on mortality of information known to the insurance

company. Adverse selection will affect mortality through information unknown to the insurance company. This problem is partially mitigated by the use of standard mortality tables. In other words, the tables are based on those able to purchase insurance at standard rates and who hence face the same price. Finally, there may be systematic errors introduced into the aggregate data by the smoothing process. However the lack of micro data requires us to make the assumption that mortality tables are unbiased estimates of the true underlying mortality of the population. ${ }^{12}$

\section{B. Results for Insurance Tables}

We turn next to discuss how insured individuals' mortality compares to mortality of the general population in the US and the UK for select and ultimate insurance tables, and in Japan only for the ultimate life insurance table. Figure 2 shows the distribution of age at death for UK Insured Males and the UK Male population. ${ }^{13}$ On average, the general population dies earlier than people who take out whole life insurance. The modal age at death in the general population is lower than the modal age at death of insured males in the UK. This is in spite of the fact that incentives in purchasing life insurance would be expected to encourage people to buy who believe that they are more likely than average to die sooner.

Figure 2 here.

There are two possible explanations for this anomalous result. The first is that insurers can clearly identify high-risk individuals at the time they apply to purchase life insurance. This would undermine the theory of adverse selection in insurance markets. The second is that we have not controlled for other differences between the population that buys life insurance and the general UK population. In particular, there may be an income effect operating, where

\footnotetext{
${ }^{12}$ This is probably true for the UK and US data; we have no information about possible biases introduced into Japanese mortality tables by the method of construction.
} 
individuals who are wealthy enough to buy life insurance are also wealthier than average, and thus have lower mortality than average. In Figure 3 we show the distribution of age at death of the female UK population and female UK purchasers of whole life policies, again conditional on reaching age 25. A similar pattern prevails.

Figure 3 here.

Equivalent graphics for the United States appear in Figures 4 and 5. While the overall pattern is similar, it appears that the modal age at death of insurance purchasers in the US is equal to that of the general population, while the mean age at death of insurance purchasers is lower. Once again, only the 'ultimate' insurance table is shown, as the 'select' table is very similar to the 'ultimate' table in spite of the longer select period.

Figures 4 and 5 here.

Similar results for Japan appear in Figures 6 and 7. Here the selection effect appears to be much smaller in Japan than it is in the UK or the US, for men and women. However in Japan, purchasers appear to have higher mortality than the general population, although this effect seems to start only at age 60 .

Figures 6 and 7 here.

Observed patterns in mortality appear in Table 1 based on A/E metrics for a male aged 35 in the US, UK, and Japan. Panel A shows results for the UK: Column 3 shows that the A/E metric for the UK male population is 100 , since the base table adopted is the UK male population table. Column 2 shows the A/E metric measured for the ultimate UK male insurance table, and hence it shows the permanent effect on mortality of purchasing insurance. The data range from 56.0 for 10-year policies in the UK, to 77.5 for whole life policies. UK male purchasers of insurance have permanently lower mortality than the population: $58.8 \%$ of the

\footnotetext{
${ }^{13}$ There is very little difference between UK Term / Whole Life and Select / Ultimate Tables, partly because of the
} 
population mortality for 5 years, $56.0 \%$ for 10 years, and $77.5 \%$ of population mortality for life. The difference between Columns 1 and 2 shows the temporary effect of selection. For 5-year policies, the select insurance mortality is 54.6 (again with a base of 100 for the UK population), compared with 58.8 for ultimate insurance mortality over that period. This indicates that people who buy insurance have lower mortality for the first 5 years of their policies than similar-aged people who have held their policies for a long time. This is in spite of the fact that insurance is a better value for those having higher mortality.

The results suggest that insurance companies in the UK are quite successful at identifying individuals with sub-standard risks. Similar results are repeated for 10-year policies, although the magnitude of the temporary reduction in mortality is lower, as we would expect if the value of information about mortality declines with time. Finally, the Panel A, line 3, shows results for whole-life insurance. Here, the temporary effect of selection on mortality all but disappears, as we would expect.

\section{Table 1 here.}

Comparable results for the US appear in Panel B. Column 3 shows the value of mortality for the US population, which is again 100 as we have used US male population mortality as a base for these calculations. The permanent effect of selection is much lower in the US than in the UK, with mortality permanently reduced to something between $68.6 \%$ and $80.6 \%$ of population mortality depending on the term of the policy. However, the temporary effect of selection is much greater in the US than in the UK. For 5-year policies, the temporary effect of selection reduces the mortality of a 35 -year old male from $73.4 \%$ to $21.2 \%$ of US male population mortality. For a 10-year policy the effect is reduced, as we would expect, but still extremely large: a reduction from $68.6 \%$ of population mortality to $29.0 \%$. Finally, for whole 
life policies, the effect is very much reduced: the temporary effect of selection lessens mortality from $80.6 \%$ of population mortality to $78.6 \%$ of population mortality. This is comparable to the UK value of $77.5 \%$ reported in column 1, Panel A. In other words, part of the dramatic difference in short-term policies across countries might be due to the much longer select period in the US. In the UK, after a policy is over five years old, it is considered to be part of the 'ultimate' group, while in the US, 25 years must pass before this occurs. As a result it appears that that the UK "ultimate" mortality is biased downward relative to the US.

Finally, results for Japan appear in Panel C of Table 1. Select mortality rates are not available since the Japanese Institute of Actuaries does not produce select tables. Nonetheless for the available data, the effect of selection on mortality is surprising. Specifically, insured lives in Japan have higher mortality than the population. This may indicate that underwriting is less rigid in Japan than in the US and the UK, or that participation in the insurance market is more widespread. It may also be an artifact of the method used to construct the Japanese insurance mortality table.

Table 2 provides comparable results for women across the three countries. Results for UK females are similar to those for UK males, although the effect of selection on mortality for whole life policies is greater for women than for men (possibly indicating a greater income effect). In the US case, the opposite is true, with insured female the mortality closer to population mortality for whole life policies. In the case of policies with shorter terms, the same pattern applies in the US as in the UK, with the effect of selection on mortality being lower for females than for males. Results for Japanese women appear in Panel C of Table 2, where again insured Japanese females appear to have much higher mortality than the Japanese female population for short policy terms, but only slightly higher mortality for very long policy terms. Table 2 here. 
In sum, these life insurance mortality tables underscore the important temporary selection effect for purchasers in the US and the UK. Life insurance buyers have lower mortality at very short policy durations than they would have at the same age if their policies had been in force for longer. At least part of this effect may be due to selective withdrawals from the pool of insured individuals. In Japan, the pattern of observed mortality is somewhat different. Insured individuals in Japan seem to have very much higher mortality than the population at shorter policy terms, and mortality roughly equal to the population at longer terms. The reasons underlying this pattern are unknown, but they may be related to weaker underwriting by Japanese insurance companies or a different method of mortality table construction.

\section{Comparing Insurance and Annuity Mortality Tables}

In this section we compare adverse selection for life insurance purchasers with that of annuity purchasers in the US, UK, and Japan. We control for factors correlated with both mortality and insurance purchasing behavior, such as income, by assuming that these correlations are independent of the type of insurance purchased. Making the further assumption that price-induced adverse selection effects are also constant across insurance types, we then quantify the effects of adverse selection on mortality by comparing the A/E metrics for the different types of insurance. Annuitants are not underwritten. In addition, compulsory annuitants do not exercise an option, so the extent of adverse selection can be assumed to be minimal. Thus the reduction in mortality of compulsory annuitants relative to the population can be regarded as a pure income effect. Voluntary annuitants are not underwritten but do exercise an option. Whole life purchasers do exercise an option though this option tends to worsen observed mortality, but they are underwritten.

Table 3 shows values of the A/E metric for voluntary as well as compulsory male and female purchasers of annuities aged 65 in the UK and the US, and voluntary annuity purchasers 
in Japan. For convenience, whole-life insurance A/E metrics have been extracted from Tables 1 and 2 and restated here. In each case, the base table is the population table for that country, as can be seen from column $5 .{ }^{14}$ Panel A of Table 3 shows the results for males. As can be seen, whole life insurance tables are between voluntary annuity and compulsory annuity tables in the UK and the US. This suggests that the effect of underwriting on the mortality of whole life policyholders more than compensates for the effect of adverse selection, but that the effect of adverse selection on voluntary annuitant mortality is more than the combined effect of underwriting and adverse selection on whole life insurance mortality. Panel B indicates results for females. In the UK, whole life purchasers exhibit lower mortality than either compulsory or voluntary annuitants, whereas in the US, the pattern is reversed. Making the same assumptions as before, females in the UK appear to be underwritten more strictly than males, while the opposite is true in the US. It might also be true that the degree of adverse selection among life insurance purchasers is heavier among females in the US than among males.

Table 3 here.

Results for Japan again differ strikingly. Among males, insurance purchasers appear to have heavier mortality than voluntary annuitant holders, while among females, mortality is roughly equal. This could be an artifact of the method used to construct the Japanese tables.

\section{Conclusion}

Our investigation discerns both temporary and permanent patterns of selection on the mortality of insured individuals in the UK and the US, even after controlling for income and

\footnotetext{
${ }^{14}$ To control for changes in population mortality over time, the annuity A/E metrics are reported relative to a base population table from the same time that the data for the annuity tables was collected. These population tables differ slightly from the population tables used to calculate the life insurance table metrics due to mortality improvements over the time between the life insurance data was collected and the time the annuity data was collected.
} 
wealth effects. The temporary effects are important at short policy durations, while the permanent effects predominate at longer policy durations. Both effects act to improve the mortality of insured lives relative to others, a surprising finding in view of classical theories of adverse selection in insurance markets. This may indicate that underwriters are relatively effective at screening out poor risks. The finding supports the view that insurance companies can better assess mortality risks better than can individuals themselves.

Our analysis might be improved by controlling for income and wealth effects, and by controlling on price-induced effects on adverse selection that may differ by product type. In addition, we do not measure the effect of selective withdrawals from the insurance pool that may be correlated with mortality. To control these, however, it would be necessary to obtain microdata that includes insurance purchase data and demographic information. Micro-level data would also allow investigators to identify separately the temporary effects of selection on annuity mortality. Such extensions will likely require access to proprietary data. 


\section{References}

Akerlof, George. “The Market for Lemons: Quality Uncertainty and the Market Mechanism.” Quarterly Journal of Economics, August 1970, 84(3), pp. 488-500.

Bowers, Newton L., Gerber, Hans U., Hickman, James C., Jones, Donald A. and Nesbitt, Cecil J. 1986. Actuarial Mathematics, Itasca, IL: Society of Actuaries.

Brown, Jeffrey, Olivia Mitchell, and James Poterba. Forthcoming. "The Role of Real Annuities and Indexed Bonds in an Individual Accounts Retirement Program.” In Risk Aspects of InvestmentBased Social Security Reform. Ed. John Y. Campbell and Martin Feldstein. [NBER WP 7005. March 1999.]

Cawley, John and Philipson, Tomas. "An Empirical Examination of Information Barriers to Trade in Insurance.” American Economic Review. 89 (4) pp. 827-846.

Executive Committee of the Faculty and Institute of Actuaries (Executive Committee). 1999. Continuous Mortality Investigation Report, 17, Faculty and Institute of Actuaries: Oxford, UK.

Finkelstein, Amy, and James Poterba. 1999. "The Market for Annuity Products in the United Kingdom.” NBER Working Paper No. 7168.

Government Actuaries’ Department (GAD). 1999. Population Projections for 1999-2000 provided in private correspondence from Steve Smallwood, Government Actuaries’ Department. United Kingdom.

Government Actuaries’ Department (GAD). 2000. Interim Population Life Table: United Kingdom. Government Actuaries’ Department. United Kingdom.

James, Estelle and Dimitri Vittas. 1999. “Annuities Markets in Comparative Perspective”. Working Paper, presented at the World Bank Conference on New Ideas About Old Age Security. Washington, D.C.: World Bank.

Japanese Institute of Actuaries. 1996. Japanese Life Insurance Mortality Tables Japanese Institute of Actuaries, Tokyo.

Knox, David. 1999. “Investigation of the Australian Annuity Market”. Working Paper, Department of Economics, University of Melbourne, Australia.

Mitchell, Olivia S., James M. Poterba, Mark Warshawsky, and Jeffrey R. Brown. 1999. "New Evidence on the Money’s Worth of Individual Annuities.” American Economic Review 89 (December).

McCarthy, David G. and Olivia S. Mitchell. 2002. "Estimating International Adverse Selection in Annuities”. North American Actuarial Journal. October: 38-54.

Philipson, Tomas J. and Gary S. Becker. 1999. “Old-Age Longevity and Mortality-Contingent Claims.” Journal of Political Economy, 106 (3) pp. 551-573.

Social Security Administration (SSA). 1999. Trustees Report: United States Life Table Functions and Actuarial Functions based on the Alternative 2 Mortality Probabilities. Washington DC: U.S. Government Printing Office.

Society of Actuaries (SOA). 1999. Exposure draft, The RP-2000 Mortality Tables. Working Paper. Schaumberg, IL: Society of Actuaries. October.

Statistics and Information Department of the Ministry of Health and Welfare, Japanese Government.1998. Japanese Life Table no. 18. Tokyo. 


\section{Figure 1: Effect of Selection on Mortality}

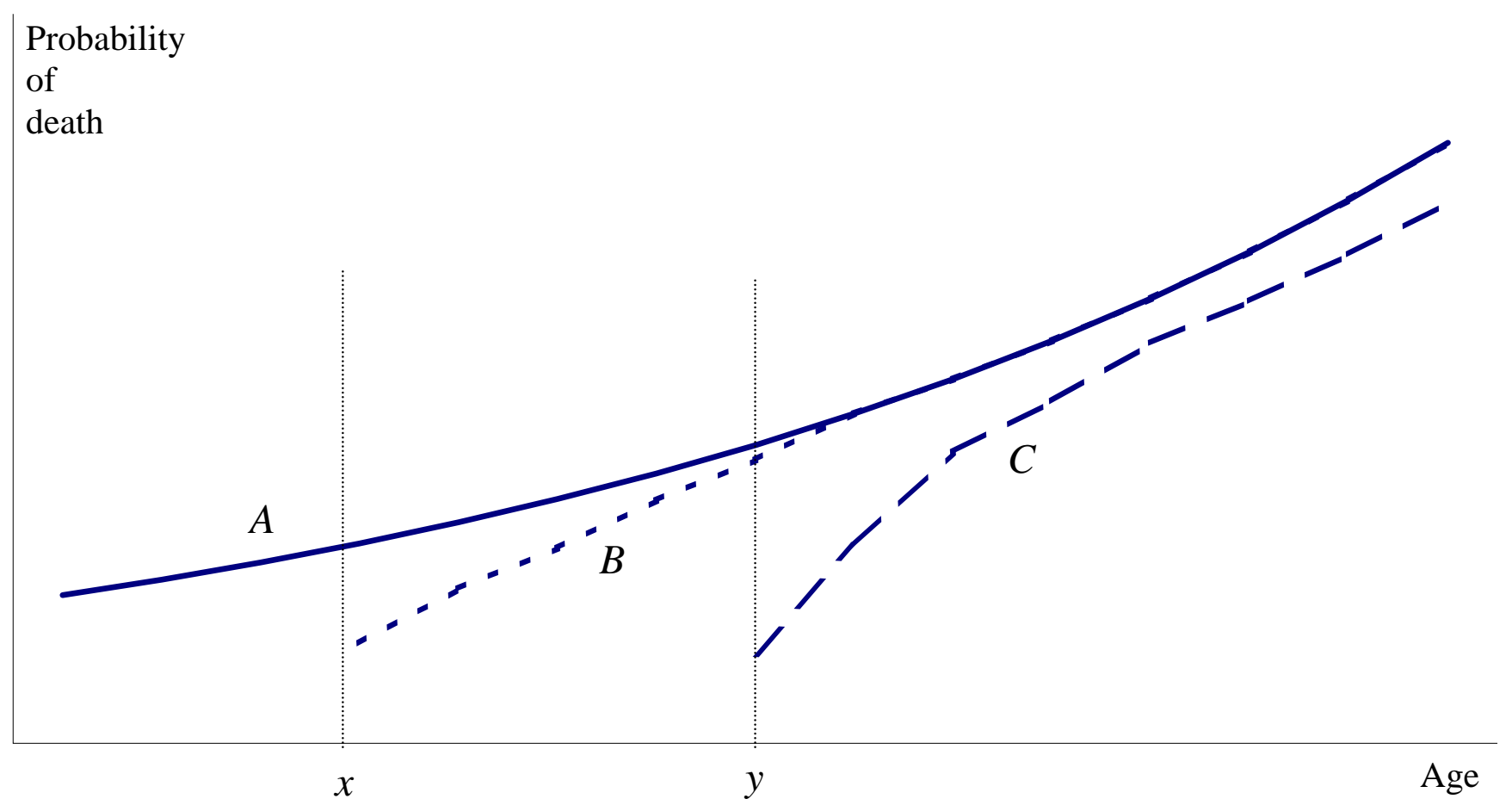

Note: Line $A$ represents group with no selection.

Line $B$ represents group undergoing temporary selection at age $x$.

Line $C$ represents group undergoing permanent and temporary selection at age $y$. 
Figure 2: Distribution of Age at Death of UK Male Population and Insured Lives:

Conditional on Reaching Age 25

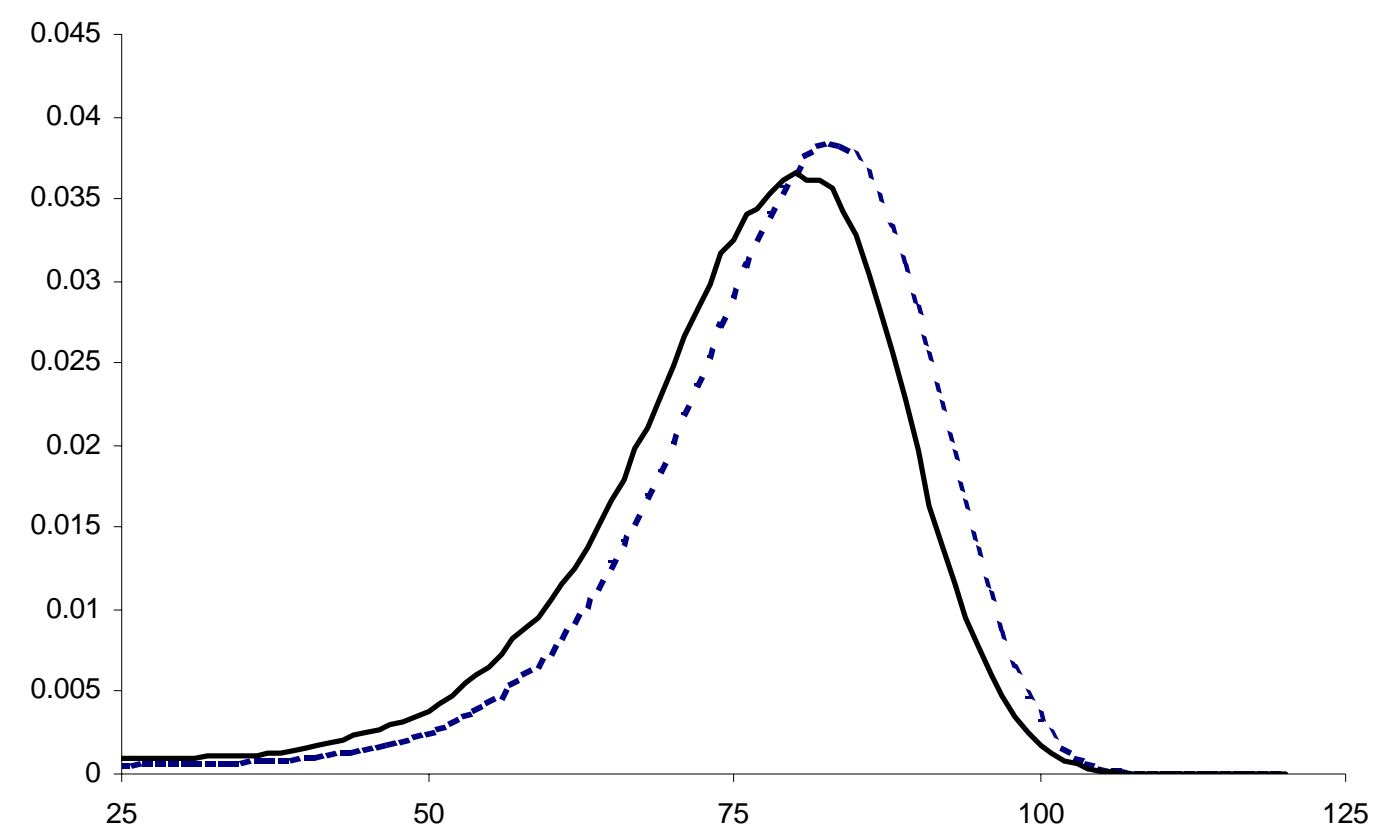

Notes: Solid line indicates UK male population. Dashed line indicates male purchasers of UK whole life policies. Graph shows distribution of age at death conditional on reaching age 25.

Source: Authors' calculations based on data from GAD(1999), GAD(2000) and CMIR(1997). 
Figure 3: Distribution of Age at Death of UK Female Population and Insured Lives:

Conditional on Reaching Age 25

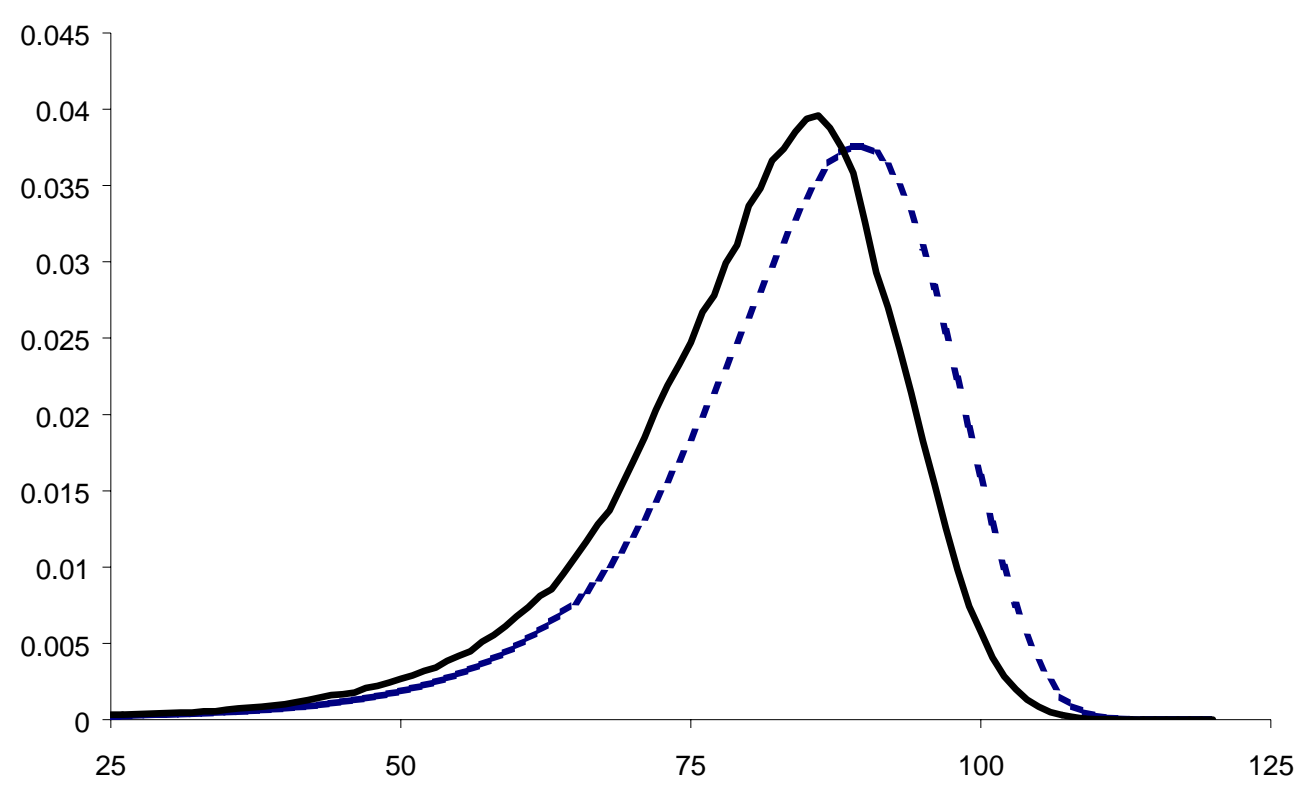

Notes: Solid line shows UK Female Population. Dashed line shows male purchasers of UK whole life policies. Graph shows distribution of age at death conditional on reaching age 25.

Source: Authors' calculations based on data from GAD(1999), GAD(2000) and CMIR(1997). 
Figure 4: Distribution of Age at Death of US Male Population and Insured Lives: Conditional on Reaching Age 25

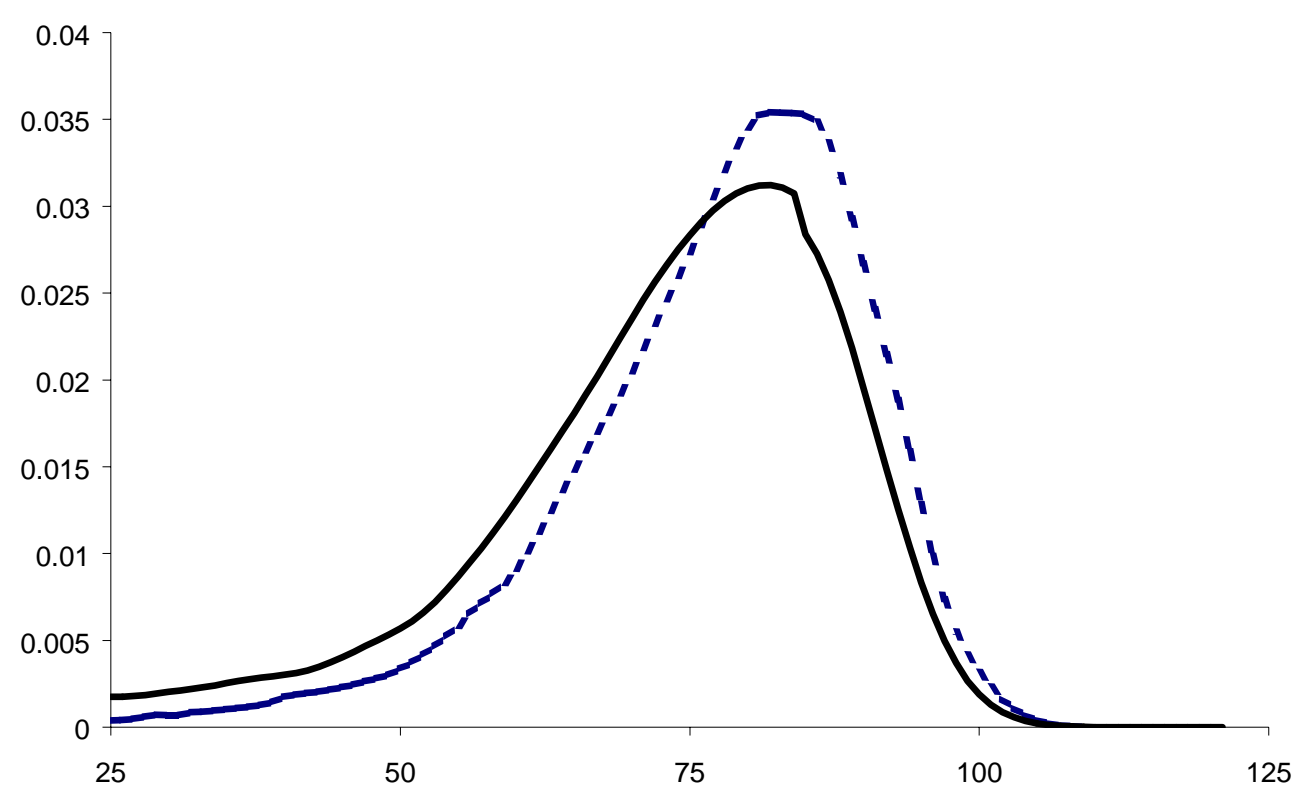

Notes: Solid line shows US male population. Dashed line shows male purchasers of US life policies. Graph shows distribution of age at death conditional on reaching age 25.

Source: Authors' calculations based on data from SSA(1999) and SOA(1997). 
Figure 5: Distribution of Age at Death of US Female Population and Insured Lives: Conditional on Reaching Age 25

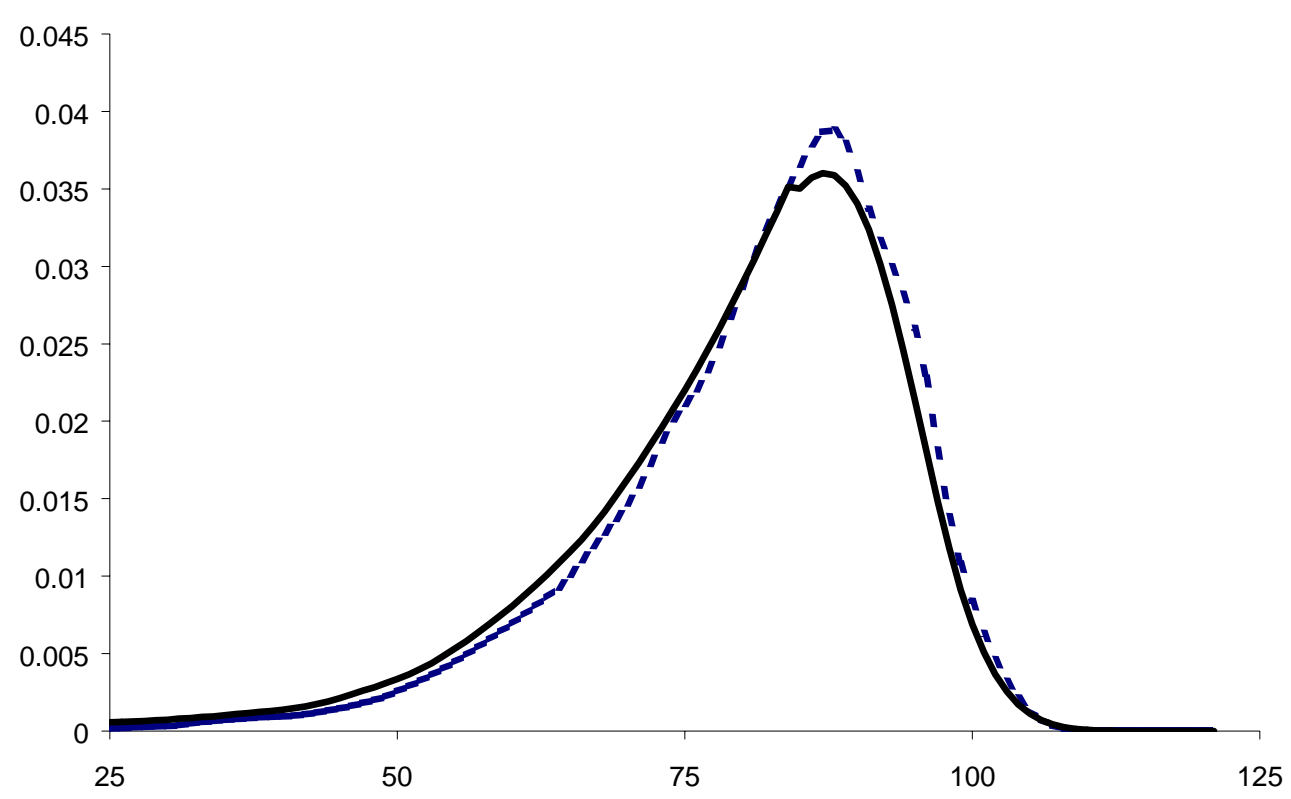

Notes: Solid line shows US female population. Dashed line shows female purchasers of US life policies. Graph shows distribution of age at death conditional on reaching age 25.

Source: Authors' calculations based on data from SSA(1999) and SOA(1997). 
Figure 6: Distribution of Age at Death of Japanese Male Pop and Insured Lives:

Conditional on Reaching Age 25

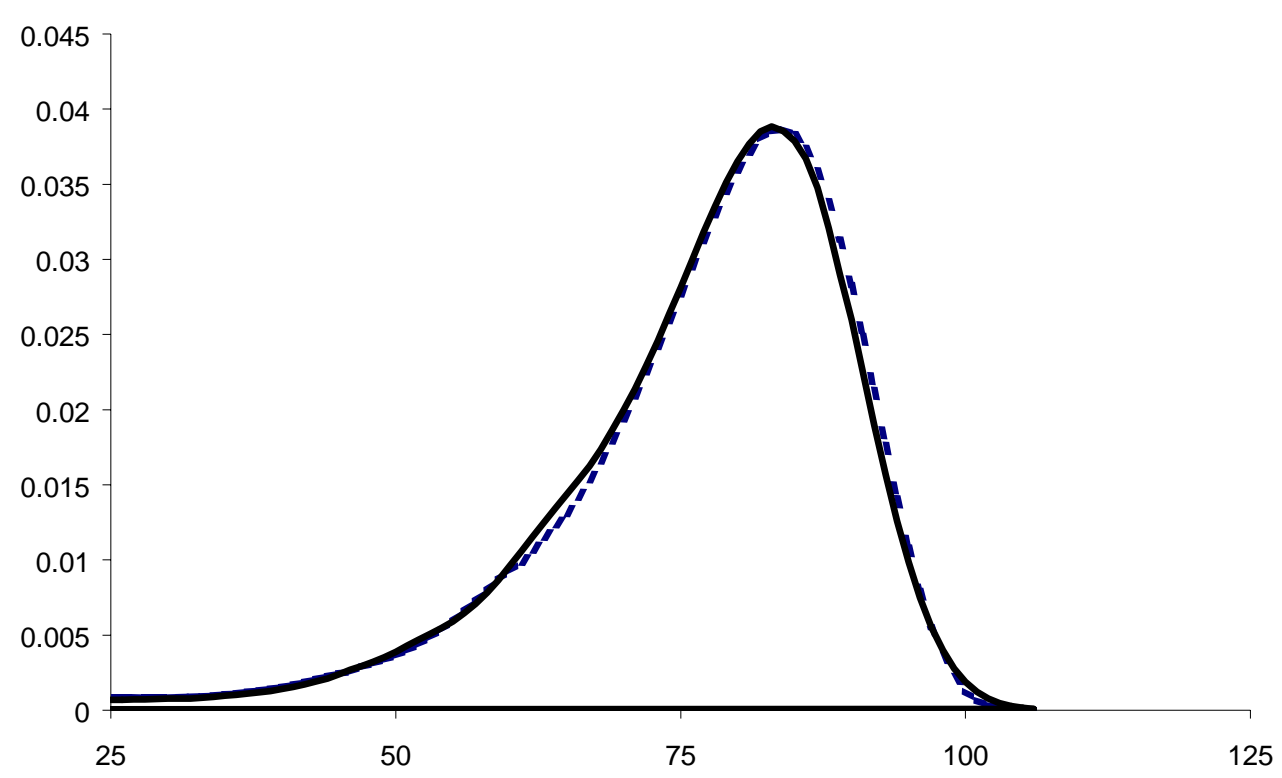

Notes: Solid line shows Japanese male population. Dashed line shows male purchasers of Japanese life policies. Graph shows distribution of age at death conditional on reaching age 25.

Source: Authors' calculations based on data from MoS(1999) and JIA(1996). 
Figure 7: Distribution of Age at Death of Japanese Female Pop and Insured Lives:

Conditional on Reaching Age 25

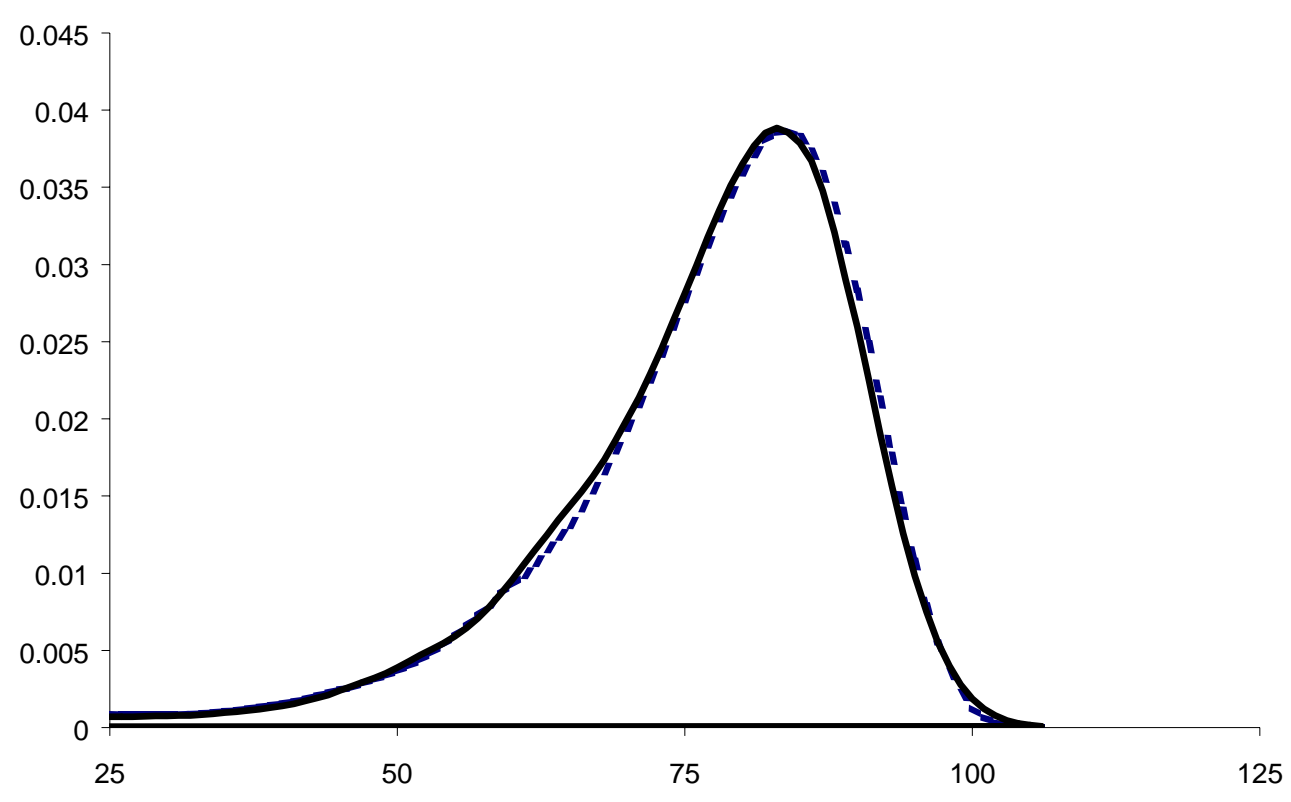

Notes: Solid line shows Japanese female population. Dashed line is female purchasers of Japanese life policies Graph shows distribution of age at death conditional on reaching age 25.

Source: Authors' calculations based on data from MoS(1999) and JIA(1996). 
Table 1: A/E Metrics for Type of Selection, Type of Policy and Country for 35-year old Male
1.
2.
3.
Select Ultimate Population
Insurance Insurance

A. UK

$\begin{array}{llll}\text { 5-year } & 54.6 & 58.8 & 100.0 \\ \text { 10-year } & 54.3 & 56.0 & 100.0 \\ \text { Whole life } & 77.5 & 77.5 & 100.0\end{array}$

B. US

$\begin{array}{llll}\text { 5-year } & 21.2 & 73.4 & 100.0 \\ \text { 10-year } & 29.0 & 68.6 & 100.0 \\ \text { Whole life } & 78.6 & 80.6 & 100.0\end{array}$

C. Japan

5-year

10-year

- $\quad 109.8 \quad 100.0$

Whole life

$\begin{array}{lll}- & 108.4 \quad 100.0\end{array}$

$-\quad 98.4 \quad 100.0$

Note: Table shows A/E metric for male aged 35, for varying policy terms and mortality tables. See text for the definition of the A/E metric.

Source: Authors' calculations. 
Table 2: A/E Metrics for Type of Selection, Type of Policy and Country for 35-year Old Female

$\begin{array}{lll}1 . & 2 . & 3 . \\ \text { Select } & \text { Ultimate } & \text { Population } \\ \text { Insurance } & \text { Insurance }\end{array}$

A. UK

$\begin{array}{llll}\text { 5-year } & 58.7 & 73.7 & 100.0 \\ \text { 10-year } & 63.5 & 69.2 & 100.0 \\ \text { Whole life } & 68.5 & 68.5 & 100.0\end{array}$

B. US

$\begin{array}{llll}\text { 5-year } & 32.8 & 78.8 & 100.0 \\ \text { 10-year } & 43.5 & 73.9 & 100.0 \\ \text { Whole life } & 90.9 & 91.6 & 100.0\end{array}$

C. Japan

5-year

10-year

Whole life

$\begin{array}{lll}\text { na } & 133.9 & 100.0 \\ \text { na } & 129.0 & 100.0 \\ \text { na } & 101.3 & 100.0\end{array}$

Source: Authors' calculations. See text for details. 
Table 3: A/E Metric for Life Annuity Purchasers Aged 65

$\begin{array}{lllll}1 . & 2 . & 3 . & 4 . & 5 . \\ \text { Voluntary } & \text { Compulsor } & \text { Whole Life } & \text { Whole Life } & \text { Population } \\ \text { y } & & & \\ \text { Annuities } & \text { Annuities } & \begin{array}{l}\text { Insurance } \\ \text { (Select) }\end{array} & \begin{array}{l}\text { Insurance } \\ \text { (Ultimate) }\end{array}\end{array}$

$\begin{array}{lrrrrr}\text { A. Males } & & & & & \\ \text { UK } & 67.5 & 82.6 & 77.5 & 77.5 & 100.0 \\ \text { US } & 65.3 & 84.0 & 78.6 & 80.6 & 100.0 \\ \text { Japan } & 81.8 & \text { na } & \text { na } & 98.4 & 100.0 \\ & & & & & \\ \text { B. Females } & & & & & \\ \text { UK } & 73.5 & 84.9 & 68.5 & 68.5 & 100.0 \\ \text { US } & 73.6 & 90.8 & 90.9 & 91.6 & 100.0 \\ \text { Japan } & 100.7 & \text { na } & \text { na } & 101.3 & 100.0\end{array}$

Source: Authors' calculations. See text for details. 